\title{
Gestão e dimensionamento de estoques de equipamentos de proteção individual de empresa distribuidora de bebidas
}

Lenicy Maciel Lima lenicy.gv@hotmail.com
IFMG, Governador Valadares, Minas Gerais, Brasil

Tatielle Menolli Longhini tatielle.longhini@ifmg.edu.br
IFMG, Governador Valadares, Minas Gerais, Brasil

\begin{abstract}
RESUMO
Este trabalho é resultado de um estudo desenvolvido em uma Distribuidora de Bebidas, onde não havia um método formal para gestão do estoque de Equipamentos de Proteção Individual. Neste cenário, as compras eram realizadas de forma intuitiva e não eram feitos registros de entrada e saída do estoque. Com isso, fez-se necessário a criação de uma planilha para controle das Fichas de EPIs e que fosse capaz de gerar dados referentes ao nível do estoque e às necessidades de compras, através do uso de métricas simples de dimensionamento. Sendo assim, este trabalho teve por objetivo propor um modelo de gestão e dimensionamento de estoque para os equipamentos de segurança. Para tal, foram utilizadas as seguintes ferramentas: primeiramente calculou-se o Estoque de Segurança a fim de indicar o estoque mínimo capaz de assegurar a disponibilidade de itens, posteriormente foi calculado o Ponto de Pedido para saber o momento certo para realização de compras e, por último, a quantidade de itens que devem ser compradas através da fórmula de Lote Econômico de Compras. Dentre os cálculos realizados, foi possível perceber que o Lote Econômico apresentou um valor muito alto e inviável à empresa, devido ao alto custo e indisponibilidade de espaço para armazenamento, e por isso, utilizou-se a fórmula de Tempo Ótimo entre Pedidos para determinar a compra de lotes econômicos de forma mensal. O método proposto foi analisado através de um gráfico, modelo dente de Serra, que possibilitou visualizar a eficácia da disponibilidade de itens em meio a flutuação de estoque.
\end{abstract}

PALAVRAS-CHAVE: Estoque. Equipamentos de Proteção Individual. Dimensionamento. 


\section{INTRODUÇÃO}

Atualmente, vive-se em um mundo altamente tecnológico e conectado, onde é possível que uma pessoa se comunique e obtenha, de forma fácil e rápida, informações de qualquer assunto ou local do mundo. Nesta realidade competitiva, os processos produtivos das empresas devem buscar melhorias por medidas estratégicas que reduzam custos, aumentem a produtividade, qualidade e aceitação no mercado.

Neste contexto, a gestão de estoque se torna um diferencial para ganhos produtivos através da economia e da busca por satisfação dos consumidores. Cabe a este setor realizar o controle de todo o material para suprir as necessidades, sempre visando diminuir a mobilização de recursos financeiros com o mesmo (VIEIRA, 2009). Basicamente, o estoque serve tanto para atender às incertezas de demanda e do tempo de ressuprimento, quanto para proteger contra aumento de preços e incentivar a economia e melhora do nível de serviço (BALLOU, 2006).

Realizar o dimensionamento de estoque é um trabalho complexo pois há muitos fatores que devem ser considerados a fim de atender a imprevisibilidade de demanda; como, por exemplo, a sua natureza espacial e/ou temporal, a extensão de sua variabilidade e seu grau de aleatoriedade (BALLOU, 2006). Para isso, existem diversas ferramentas para auxiliar no processo de previsão de demanda e dimensionamento de estoque.

Segundo Slack et al. (2013), todas as operações mantem um estoque de algum tipo; na área da Segurança do Trabalho não é diferente. Neste caso, os gestores precisam manter o estoque de Equipamento de Proteção Individual (EPI) e, além disso, deve-se garantir a eficiência e controle do mesmo, para que o trabalhador tenha sempre a seu alcance os equipamentos necessários para sua segurança. É papel do empregador reduzir qualquer risco que ameace a segurança do funcionário (BRASIL, 1988).

Os EPIs são equipamentos de uso individual utilizados durante o trabalho para proteger o colaborador de riscos que ameacem a sua segurança e saúde. A empresa deve fornecê-los de forma gratuita e adequada, além de garantir todo o seu controle, não deixando com que o trabalhador utilize EPIs sem o Certificado de Aprovação (CA) ou com ele estando fora da data de validade (BRASIL, 2018; BRASIL, 1943). Além disso, deve assegurar a substituição imediata em casos de danos ou extravios e o registro de fornecimentos por empregado. A falta de utilização de EPIs pelas empresas pode ser passível de sanções legais para a empresa, podendo ela ser penalizada com multas pelo Ministério do Trabalho e Emprego, caso não sejam seguidas as normas regulamentadoras (RODRIGUES; SANTOS, 2017).

No ano de 2017, segundo o Anuário Estatístico de Acidentes do Trabalho (2017), houve cerca de 594.405 acidentes de trabalho somente no Brasil, sendo as classificações mais comuns para as doenças ocasionadas: ferimento do punho e da mão, fratura ao nível do punho e da mão e luxação/entorse/distensão das ligações ao nível do tornozelo e pé.

Além disso Linhares et al. (2016) constataram que, em cerca de $73,33 \%$ das ocorrências dos acidentados em obras civis, o não uso de EPIs foi apontado como 
um dos fatores agravantes ou causadores do acidente (LINHARES et al., 2016). Por isso, esses itens precisam de um controle adequado tanto no seu armazenamento e distribuição quanto na análise e planejamento de compras, para cumprimento de requisitos legais e operacionais (SALIBA, 2016).

A fim de evitar a falta de itens, a empresa precisa garantir que haja um estoque de segurança para casos onde o funcionário precisa realizar a troca de EPI, em casos de urgência. Para isso, segundo Chiavenato (2005), devem ser utilizadas técnicas para controle e dimensionamento de estoques para estabelecer níveis adequados ao abastecimento da empresa - sem que ocorra volumes excessivos ou insuficientes.

Algumas das técnicas que podem ser utilizadas neste processo são: a definição do ponto de ressuprimento, realização da previsão de demanda, cálculo do estoque de segurança e do lote econômico de compras, elaboração da curva $A B C$ e entre outros. Portanto, esta pesquisa tem como objetivo responder a seguinte pergunta: De que maneira a gestão e dimensionamento de estoque influenciam nas decisões de ressuprimento de EPIs em uma empresa distribuidora de bebidas?

Assim, este trabalho visa avaliar as particularidades dos Equipamentos de Proteção Individual utilizados pelos funcionários de uma Distribuidora de bebidas, bem como propor métricas de acompanhamento e dimensionamento de estoque de EPIs baseado na utilização de estoques de segurança e lotes econômicos a fim de reduzir os custos e melhorar a qualidade de serviço.

\section{FUNDAMENTAÇÃO TEÓRICA}

Neste capítulo serão apresentados os principais temas a serem abordados no trabalho, em que serão estudados os conceitos ligados ao estoque, ferramentas para sua gestão e técnicas para seu dimensionamento, bem como assuntos relacionado aos EPIs, como suas particularidades e requisitos.

\section{GESTÃO DE ESTOQUES}

Segundo Paoleschi (2013), estoque é toda e qualquer quantidade de material armazenada de forma improdutiva durante um certo período de tempo e que tem por objetivo suprir as necessidades oportunas de uma organização. Ainda, de acordo com Slack et al. (2013), a existência do estoque se dá pela acumulação de recursos materiais existentes devido a diferença de ritmo entre suprimento e demanda.

O Quadro 1 demonstra algumas das razões que levam a empresa a optar pela utilização de estoques, bem como as situações em que podem ser utilizados: 
Quadro 1 - Razões para utilização de estoques

\begin{tabular}{|c|c|}
\hline Razão do Estoque & Situação de ocorrência \\
\hline $\begin{array}{c}\text { independência } \\
\text { entre etapas do } \\
\text { processo }\end{array}$ & $\begin{array}{c}\text { Estoques de segurança irão garantir com que as etapas de um } \\
\text { processo sejam independentes, porque se caso acontecer um } \\
\text { problema em uma das etapas, o estoque irá amortizar e garantir os } \\
\text { insumos necessários para a continuidade do processo. }\end{array}$ \\
\hline $\begin{array}{c}\text { Permitir uma } \\
\text { produção } \\
\text { constante }\end{array}$ & $\begin{array}{c}\text { Sistemas com variação de demanda sazonal conseguem manter o } \\
\text { mesmo ritmo de produção durante todo o ano. Nos períodos de } \\
\text { baixa demanda é produzida a mesma quantidade de material, este } \\
\text { material é estocado para atender os momentos de alta. }\end{array}$ \\
\hline $\begin{array}{c}\text { Possibilitar o uso } \\
\text { de lotes }\end{array}$ & $\begin{array}{c}\text { Em algumas situações são aconselhadas compras ou produça em } \\
\text { lotes econômicos, que geralmente são em quantidades maiores } \\
\text { que as necessárias, a partir daí estes materiais que não são } \\
\text { utilizados são estocados para uso futuro. }\end{array}$ \\
\hline $\begin{array}{c}\text { Reduzir os lead } \\
\text { times produtivos }\end{array}$ & $\begin{array}{c}\text { Estoques intermediários garantem prazos de entrega de produtos } \\
\text { com menor tempo e consequentemente aumenta a satisfação do } \\
\text { cliente. }\end{array}$ \\
\hline $\begin{array}{c}\text { Servir como fator } \\
\text { de segurança }\end{array}$ & $\begin{array}{c}\text { Estoques de segurança asseguram a empresa em casos de falhas } \\
\text { na previsão de demanda, atraso na entrega dos fornecedores e } \\
\text { abtrasos da produção. }\end{array}$ \\
\hline financeiras & $\begin{array}{c}\text { Acontece quando a compra de matéria prima é feita em grande } \\
\text { escala para conseguir descontos ou quando se aumenta o estoque } \\
\text { de produtos acabados a partir da análise de tendência de aumento } \\
\text { de preço de venda no mercado. }\end{array}$ \\
\hline
\end{tabular}

Fonte: Adaptado de Tubino (2009, p. 67-68)

Além disso, é comum que os gestores tenham pensamentos diferentes no que se refere à utilização de estoques. Por um lado, acreditam que é algo imprescindível e que vai garantir segurança à empresa em relação a variações inesperadas de demanda. Por outro, pensam no alto custo que este estoque vai gerar, além da possibilidade daqueles itens se tornarem obsoletos ou passarem do prazo de validade (SLACK et al., 2013).

Sendo assim, o gerenciamento de estoque se faz necessário para criar um ponto de equilíbrio entre esses dois pensamentos e assegurar segurança e economia ao mesmo tempo. Paoleschi (2013) diz que essa é uma tarefa complexa, mas que se caso for feita da forma correta irá eliminar desperdícios de tempo, dinheiro e espaço, além de garantir um bom atendimento ao cliente.

Segundo Tubino (2009), o gerenciamento de estoque é responsável por buscar a economia através da definição adequada de quanto e quando comprar, fabricar ou montar de cada item necessário à empresa, podendo ser definido o tamanho dos lotes, formas de reposição e estoques de segurança. Martins e Alt (2009) dizem que essa gestão é necessária não somente pela economia de gastos, mas também pela vantagem competitiva e precisão no atendimento as demandas dos clientes.

No caso em estudo, a falta de EPI em estoque pode ocasionar diversos problemas para empresa, que vão desde a compra por preços elevados devido à necessidade não prevista, até o acontecimento de um acidente com danos acima do esperado, fato esse devido ao funcionário não estar utilizando o EPI adequado (MOTTA; MARINS, 2012). 
Portanto, de acordo com Vieira (2009), o administrador de estoques deve buscar os seguintes objetivos através de seu trabalho: definir o momento da compra, calcular a quantidade necessária, buscar economia de preços, atender aos níveis de segurança e garantir qualidade no serviço ao cliente. Atingindo todos estes objetivos será possível satisfazer a disponibilidade de itens através de menores investimentos.

\section{TÉCNICAS DE DIMENSIONAMENTO E GESTÃO DE ESTOQUES}

Segundo Chiavenato (2005), dimensionamento do estoque é a área responsável por estabelecer as quantidades de itens necessários para suprir as demandas de uma organização de forma que não ocorra estoques excessivos, nem insuficientes. Deve-se tentar fugir desses dois extremos e garantir o estoque adequado, tendo em vista que os estoques excessivos podem levar a desperdícios e perdas financeiras e os estoques insuficientes podem ocasionar em interrupções da produção e insatisfação do cliente por falta de material.

Viana (2002) diz que este dimensionamento deve ser realizado através de técnicas que possibilitem equilibrar o consumo, além de acompanhar a evolução da cadeia de suprimentos. Portanto, neste tópico serão apresentadas algumas dessas técnicas que podem auxiliar no dimensionamento e consequentemente na gestão do estoque. Sendo assim, serão utilizadas quatro técnicas relacionadas ao desenvolvimento da gestão e dimensionamento de estoque deste trabalho, são elas: Ponto de Pedido, Estoque de Segurança, Tempo de Ressuprimento e Lote Econômico de Compras.

\section{Ponto de Pedido}

O ponto de pedido ou ponto de ressuprimento consiste no nível de estoque indicativo da necessidade de ressuprimento de produtos (TEIXEIRA, 2006). Segundo Pozo (2010), este nível de estoque é capaz de assegurar a disponibilidade de material enquanto se aguarda a chegada dos novos produtos.

O gráfico da Figura 1 é conhecido por gráfico dente de Serra e representa o funcionamento do Ponto de Ressuprimento, de acordo com a quantidade de material em estoque e o tempo decorrido. $O$ ponto de pedido é representado por $\mathrm{q}_{3}$ e indica o momento em que um novo pedido de compra deve ser emitido a fim de que o estoque não seja zerado. Este ponto é calculado com base no tempo em que o pedido demora para poder ser utilizado e no estoque de segurança indicado por $\mathrm{q}_{2}$. 
Figura 1 - Gráfico do Ponto de Ressuprimento

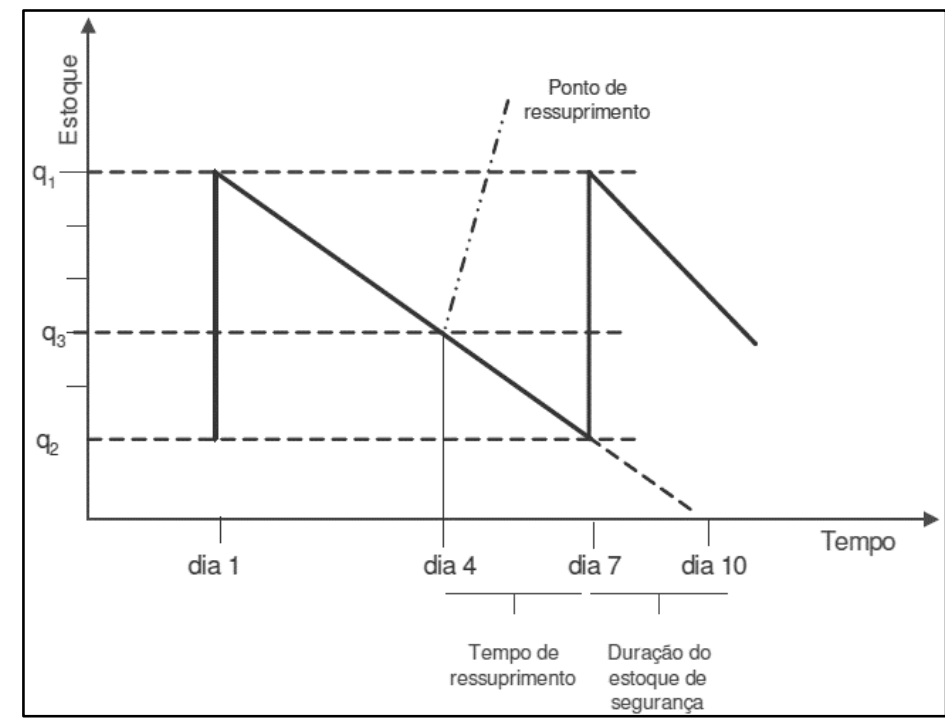

Fonte: Peinado e Graeml (2007)

Segundo Chiavenato (2005), através do gráfico do ponto de pedido é possível perceber também que o estoque de segurança somado ao lote de compra é igual ao estoque máximo, representado por $\mathrm{q}_{1}$. Intuitivamente ao gráfico, Teixeira (2016) define o cálculo necessário para o ponto de ressuprimento. Este cálculo está representado pela Equação 1.

$$
\mathrm{PP}=\mathrm{C} \times \mathrm{TR}+\mathrm{ES}
$$

Onde:

$$
\begin{aligned}
& \text { PP = Ponto de Pedido; } \\
& C \text { = Consumo médio; } \\
& \text { TR = Tempo de Reposição; } \\
& \text { ES = Estoque de Segurança. }
\end{aligned}
$$

Logo, conclui-se que o ponto de pedido é um indicador de estoque que ao ser atingido, gera a necessidade de reposição do material. A ideia é que a quantidade restante em estoque suporte o consumo até que o tempo de reposição acabe, não ocasionando falta de material à empresa (DIAS, 2015).

\section{Estoque de Segurança}

Segundo Alves (2017), o estoque de segurança é a quantidade mínima que uma organização deve manter a fim de assegurar a disponibilidade de material em casos de atraso na entrega ou variações de demanda. De acordo com Dias (2015), o estoque de segurança deve ser tratado como uma quantidade morta, ou seja, sua finalidade é ser utilizada apenas em casos atípicos de necessidade.

Conforme Taylor (2006), não existe uma quantidade de estoque que consiga evitar totalmente a escassez de materiais, porém a adoção de estoques mínimos 
pode fazer com que a empresa reduza esses riscos. Da mesma forma, Vieira (2009) afirma que o estoque de segurança é o que permite a empresa reduzir os riscos de falta de materiais por diversos motivos como: atraso dos fornecedores, entrega de materiais com qualidade ruim, condições climáticas, problemas com transporte, quebras de máquinas e aumento de demanda.

Pozo (2010) explica que muitas das vezes parece ser mais cômodo manter um estoque de segurança alto e que seja capaz de suprir toda a variação que o sistema possa assumir, porém isso implica em investimentos para a empresa. Portanto, é necessário determinar um estoque de segurança que seja capaz de unir dois pontos importantes, o suprimento da cadeia produtiva e economia com gastos referente às aquisições e manutenção do estoque.

Segundo Peinado e Graeml (2007), o estoque de segurança pode ser calculado de diversas formas a depender da variação de demanda e do tempo de ressuprimento. Em casos onde ambos são variáveis, este estoque pode ser calculado pela Equação 2:

$$
\mathrm{ES}=\mathrm{Z} \times \sqrt{\left(\overline{\mathrm{TR}} \times \sigma_{\mathrm{D}}^{2}\right)+\left(\overline{\mathrm{D}}^{2} \times \sigma_{\mathrm{TR}}^{2}\right)}
$$

Onde:

$\mathrm{ES}=$ Estoque de segurança;

$\mathrm{Z}$ = Número de desvios padrão;

$\mathrm{TR}$ = Tempo médio de ressuprimento;

$\mathrm{D}=$ Demanda média no período;

$\sigma_{D}=$ Desvio padrão da demanda;

$\sigma_{\mathrm{TR}}=$ Desvio padrão do tempo de ressuprimento.

O número de desvios padrão é dado em relação ao nível de serviço que a empresa deseja oferecer. Ou seja, caso a empresa opte por garantir a disponibilidade de itens em $98 \%$ dos casos, ela deve adotar o desvio padrão de 2,055; conforme demonstra a Tabela 1 (CORRÊA; CORRÊA, 2012).

Tabela 1 - Desvio padrão em função do nível de serviço

$\begin{array}{cc}\text { Nível de Serviço } & \text { Desvio Padrão (Z) } \\ 50 \% & 0,254 \\ 60 \% & 0,525 \\ 70 \% & 0,842 \\ 80 \% & 1,037 \\ 85 \% & 1,282 \\ 90 \% & 1,645 \\ 95 \% & 1,751 \\ 96 \% & 1,880 \\ 97 \% & 2,055 \\ 98 \% & \end{array}$




\begin{tabular}{cc} 
Nível de Serviço & Desvio Padrão (z) \\
\hline $99 \%$ & 2,325 \\
$99,9 \%$ & 3,100 \\
$99,99 \%$ & 3,620 \\
\hline
\end{tabular}

Fonte: Corrêa e Corrêa (2012, p. 522)

Portanto, é possível calcular o estoque de segurança de cada item necessário à organização a fim de evitar os riscos de escassez relacionados às variações de demanda e atrasos na entrega e garantir que a empresa os tenha sempre disponíveis.

\section{Tempo de Reposição}

Segundo Fenili (2015), o tempo de reposição, também conhecido por lead time, consiste no intervalo de tempo entre a emissão do pedido de compra até a chegada e liberação do pedido ao almoxarifado. Da mesma forma, Chiavenato (2005) diz que este é tempo gasto desde o momento em que é verificado a necessidade de compra, até a chegada do material na empresa.

De acordo com Teixeira (2016), o lead time deve levar em consideração três tempos diferentes: o tempo de emissão de pedido, o tempo de preparação do pedido e o tempo de transporte. De forma semelhante, Pozo (2010) define o cálculo do tempo de ressuprimento como sendo o resultado da soma de três tempos, como demonstra a Equação 3.

$$
\mathrm{TR}=\mathrm{T} 1+\mathrm{T} 2+\mathrm{T} 3
$$

Onde:

T1 = Tempo de elaboração e confirmação do pedido junto ao fornecedor;

$\mathrm{T} 2$ = Tempo que o fornecedor precisa para processar e entregar o pedido;

T3 = Tempo para processar a liberação do pedido na empresa.

A partir da fórmula, é possível calcular o tempo de ressuprimento de cada item, a fim de utiliza-lo no dimensionamento do estoque. Porém, os gestores têm que levar em conta que este tempo pode sofrer variações por diferentes motivos, como: atrasos na compra, no transporte ou no recebimento; além de considerar que o ideal é possuir valores de lead time pequenos, já que estes influenciam diretamente na gestão de estoque (PEINADO; GRAEML, 2007).

Dessa forma, deve-se buscar por maneiras de diminuir o lead time, devido ao seu impacto direto sobre a definição do estoque mínimo e do ponto de reposição. O cuidado com o cálculo deve ser redobrado, tendo em vista que ambos aumentam proporcionalmente ao tempo de ressuprimento, acarretando em investimentos maiores à empresa. 
Outra questão em que os gestores devem ficar atentos na hora de realizar a gestão de estoques é na quantidade de materiais a serem repostos a fim de tornar os custos menores. Para isso, existe uma variável denominada por Lote Econômico de Compras (LEC) que é responsável por definir a quantidade ideal de itens a serem comprados, onde os custos de estocagem e aquisição sejam mínimos (GONÇALVES, 2004).

Segundo Slack et al. (2013), a abordagem do LEC tem como objetivo encontrar um ponto de equilíbrio entre vantagens e desvantagens em se manter um estoque, levando-se em conta a demanda dos produtos e os custos envolvidos de manutenção, aquisição e desvalorização do estoque.

De acordo com Vieira (2009) o cálculo do lote econômico pode ser realizado através da Equação 4.

$$
\mathrm{LEC}=\sqrt{\frac{2 \times \mathrm{CE} \times \mathrm{DA}}{\mathrm{CMA} \times \mathrm{VUP}}}
$$

Onde:

LEC = Lote Econômico de Compras;

DA = Demanda anual de itens;

$\mathrm{CE}=$ Custo de emitir e colocar o pedido;

CMA = Custo de manutenção anual do estoque;

VUP = Valor unitário do produto.

Sendo assim, é possível definir a quantidade de itens a serem comprados a cada reposição do estoque. Além disso, segundo Corrêa e Corrêa (2012), é possível calcular o tempo ótimo de intervalo entre os pedidos através da Equação 5.

$$
t_{f}=\frac{\text { LEC }}{D A}
$$

Onde:

$\mathrm{t}_{\mathrm{f}}=$ Intervalo de tempo ótimo;

LEC = Lote Econômico de Compras;

DA = Demanda anual de itens.

Portanto, a partir do tempo ótimo entre pedidos, a empresa poderá se planejar a respeito do capital a ser investido na aquisição dos novos pedidos de materiais. 
De acordo com Alves (2013), EPI é todo e qualquer equipamento utilizado de forma individual pelo trabalhador que tem por objetivo protege-lo dos riscos inerente ao trabalho. Da mesma forma, Gonçalves (2000, p. 136) define os EPIs como sendo "todo equipamento de uso pessoal cuja finalidade é proteger a saúde ou a integridade física do trabalhador da exposição a agentes físicos, químicos, mecânicos ou biológicos, por ventura, presentes no ambiente de trabalho".

Segundo Saliba (2016), o uso dos EPIs deve ser considerado como uma alternativa para a redução dos riscos do trabalho e para prevenção de acidentes a ser adotada quando todas as outras alternativas de controle de segurança coletiva forem esgotadas.

A Norma Regulamentadora - NR 6 (BRASIL, 2018) rege as normativas que devem ser seguidas visando a proteção do trabalhador através da utilização desses equipamentos de proteção, bem como define as obrigações da empresa, do trabalhador e do fabricante quanto ao seu uso e manutenção, além das exigências para cada tipo de trabalho.

Do mesmo modo, a Consolidação das Leis Trabalhistas (BRASIL, 1943) aborda as obrigações do empregador em fornecer os EPIs adequados ao risco de cada tipo de atividade, de forma gratuita e sempre que necessário. Em contrapartida, está a obrigação do funcionário o uso do EPI, além de se responsabilizar por sua guarda e conservação.

Além disso, a NR 6 define que as empresas devem garantir apenas o fornecimento de EPIs que possuam a Certificação de Aprovação concedida pelo órgão nacional competente em questão de segurança e saúde no trabalho do Ministério do Trabalho e Emprego. Além de possuir o registro dos equipamentos disponibilizados a cada funcionário através de fichas, livros ou sistema eletrônico (BRASIL, 2018).

Levando em conta a indicação do EPI adequado, a mesma deve ser realizada pelo Técnico de Segurança do Trabalho através da avaliação dos riscos pertinentes ao trabalho. Porém, é importante considerar a participação e opinião dos funcionários para que não sejam adotados equipamentos que sejam incômodos e ineficientes (SALIBA, 2016).

A NR 6 detalha os equipamentos que podem ser utilizadas para garantir a proteção em cada tipo de atividade (BRASIL, 2018). Diante disso, é importante analisar os riscos presentes no trabalho e através disto, identificar os EPIs mais adequados para cada tipo de função.

\section{METODOLOGIA}

A metodologia pode ser caracterizada pela abrangência de um conjunto de técnicas utilizadas para orientar o desenvolvimento de uma determinada pesquisa. Ela tem como objetivo direcionar o autor nas atividades recorrentes à pesquisa, tornando as etapas mais claras, sistematizando a forma com que o 
pesquisador compreende e descreve o estudo, além de classifica-la quanto ao tipo de pesquisa (VALENTIM, 2005).

Dessa forma, neste capítulo, serão apresentados os métodos a serem utilizados para realização desta pesquisa, bem como os instrumentos que visam auxiliar na coleta de dados e etapas seguidas.

\section{CLASSIFICAÇÃO DA PESQUISA}

Segundo Gerhardt e Silveira (2009), uma pesquisa deve ser classificada quanto a sua finalidade, natureza, abordagem, objetivos e quanto aos seus procedimentos de análise e coleta de dados.

Sendo assim, é possível classificar a finalidade desta pesquisa como sendo do tipo aplicada, tendo em vista que seu objetivo é a aplicação prática de conhecimentos para solução de problemas em relação a gestão de estoque de EPIs da empresa em estudo (VALENTIM, 2005).

A natureza desta pesquisa será quantitativa e qualitativa, pois os dados serão mensurados em números, classificados e analisados, utilizando-se de técnicas estatísticas tanto na coleta de dados quanto no tratamento de informações e além disso, os dados serão analisados de forma qualitativa em relação às especificações dos EPIs e cargo dos funcionários (DIEHL, 2004).

Este trabalho caracteriza-se como um estudo de caso, pois possibilitará o desenvolvimento de um breve estudo dentro de uma organização. Neste tipo de estudo busca-se investigar, de forma exaustiva, um fenômeno atual dentro de uma realidade e contexto específico (YIN, 2005).

A coleta dos dados a serem utilizados no decorrer desta pesquisa será realizada através de duas técnicas: análise documental e pesquisa-ação. Segundo Lakatos e Marconi (2001), a análise documental consiste na coleta de dados através de documentos particulares ou públicos, desta maneira serão analisados alguns documentos próprios da empresa, como: fichas de EPI dos funcionários Anexo A, catálogo de EPIs e relatórios de compras. Já a pesquisa-ação constitui-se de uma pesquisa que através da participação do autor, busca-se a solução de um problema e a geração de conhecimentos (VERGARA, 2000).

Os dados serão analisados por meio de dois métodos diferentes, sendo eles: análise estatística descritiva e triangulação de dados. Estes métodos estão melhor descritos no Quadro 2.

Quadro 2 - Métodos de análise de dados

\begin{tabular}{|c|c|c|}
\hline Método & Descrição & Autor \\
\hline Análise & Tem como objetivo representar os dados de forma clara & Lakatos \& \\
Estatística & por meio de tabelas e gráficos para analisa-los através da & Marconi \\
Descritiva & adoção de medidas estatísticas ou indicadores. & $(2001)$ \\
\hline $\begin{array}{c}\text { Triangulação } \\
\text { de dados }\end{array}$ & Esta técnica abrange a validação dos dados coletados & Creswell \\
mediante comparação entre as fontes de dados. & $(2003)$ \\
\hline
\end{tabular}

Fonte: Autoria própria (2020).

Dessa maneira, busca-se através das técnicas metodológicas adotadas desenvolver um trabalho, cujo objetivo geral adotado pode ser classificado como 
descritivo, onde é estudado e analisado as características de certa população e/ou fenômeno e identificar a existência de relação entre suas variáveis, bem como analisar a natureza dessas relações (GIL, 2002). Neste contexto, serão estudadas as características da atual gestão de estoque e analisado a relação entre variáveis de dimensionamento e decisões de ressuprimento.

\section{METODOLOGIA DO PROJETO DE PESQUISA}

Este trabalho foi realizado em uma empresa Distribuidora de Bebidas situada na cidade de Governador Valadares - MG. Trata-se de um estudo de caso que busca estudar a influência da gestão e dimensionamento de estoque nas decisões de ressuprimento de Equipamentos de Proteção Individual utilizados pelos funcionários da empresa.

Em resumo, a Figura 2 demonstra as etapas que serão seguidas a fim de atingir o proposto neste trabalho.

Figura 2 - Etapas do estudo

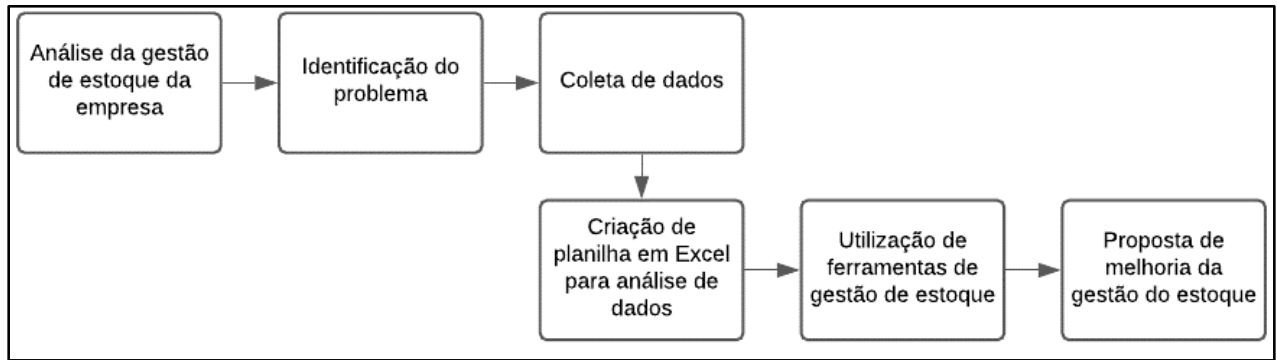

Fonte: Autoria própria (2020).

Sendo assim, a princípio foi realizada uma análise crítica acerca do funcionamento da atual gestão de estoque de EPIs da empresa em estudo, visando o entendimento de como funciona a atual gestão e quais os problemas que podem ser estudados, buscando-se uma melhoria. Através desta análise, foi possível identificar a dificuldade em se manter um estoque com níveis adequados que consiga garantir o abastecimento de equipamentos em eventualidades.

Depois desta análise e identificação do problema a ser solucionado, foram coletados os dados para auxiliar no dimensionamento de estoque pretendido. $O$ foco de coleta será realizado por meio das fichas de EPIs - Anexo A, onde será possível verificar o registro de entregas de equipamentos para cada funcionário. Além disso, serão coletados relatórios de compras e o catálogo de EPIs utilizado pela empresa. Os dados considerados nesta pesquisa serão do período de janeiro de 2019 a setembro de 2019.

Posteriormente, será criada uma planilha em Excel para tabulação e análise dos dados coletados. Nesta planilha será possível calcular a periodicidade média com que os funcionários trocam cada um de seus equipamentos de proteção, para assim utilizar as ferramentas de gerenciamento de estoques e realizar o seu dimensionamento através das métricas estudadas. Por fim será realizada uma proposta de melhoria na gestão utilizada para controle de estoque de EPIs da empresa, através da adoção de uma sistemática de controle e ressuprimento. 
Neste capitulo busca-se apresentar as principais etapas do estudo de caso realizado, tais como: dados coletados no decorrer do estudo, discussão das análises realizadas e resultados obtidos.

\section{ESTUDO DE CASO}

Este trabalho foi aplicado em uma Distribuidora de Bebidas, situada no interior de Minas Gerais (MG), que realiza a revenda dos produtos de uma companhia de bebidas conhecida mundialmente. A empresa foi fundada no ano de 1969 e atende, atualmente, a 105 cidades e seus distritos na região leste de MG. Dentre os produtos oferecidos pela empresa, estão as bebidas: refrigerantes, cervejas, energéticos, isotônicos, sucos e chopes, de variadas marcas.

O serviço da empresa consiste na venda e entrega desses produtos aos seus clientes e para isso conta com 236 funcionários divididos em seis setores diferentes, como demostra o Quadro 3, com dados coletados em outubro de 2019. Porém, é importante ressaltar que estes dados variam de forma frequente em razão do alto índice de rotatividade de funcionários, principalmente nos setores de Distribuição Urbana e Apoio Logístico.

Quadro 3 - Relação da quantidade de funcionários

\begin{tabular}{|c|c|l|}
\hline Setor & Quantidade funcionários & \multicolumn{1}{|c|}{ Descrição } \\
\hline Administrativo & 42 & Cargos de função administrativa \\
\hline Apoio logístico & 42 & Funcionários do Armazém e Oficina \\
\hline $\begin{array}{c}\text { Distribuição } \\
\text { urbana }\end{array}$ & 81 & $\begin{array}{l}\text { Funcionários da Distribuição } \\
\text { (Motoristas e Ajudantes) }\end{array}$ \\
\hline Puxada & 10 & Motoristas de Carreta \\
\hline Vendas & 61 & $\begin{array}{l}\text { Vendedores Externos e Internos, } \\
\text { Supervisores e Promotores }\end{array}$ \\
\hline
\end{tabular}

Fonte: Autoria própria (2020).

O empreendimento se destaca por oferecer comodidade através de um serviço de qualidade, entregando a seus clientes o produto desejado com preços e benefícios atrativos. Além disso, é oferecido aos clientes fidelizados condições especiais de pagamento, descontos, comodatos de materiais e utensílios de merchandising.

\section{SITUAÇÃO ANALISADA}

Anteriormente, foi vista a necessidade do fornecimento de EPIs, bem como a importância de uma gestão de estoques para otimizar os gastos referentes a este estoque e a garantia de segurança aos funcionários. Desse modo, este estudo foi desenvolvido no setor de Segurança de Trabalho da empresa, mais especificamente na gestão do estoque de EPIs. 
Através da análise do estoque de EPIs foi possível notar que a empresa apresenta uma gestão de estoque ineficaz para itens tão importantes à segurança dos trabalhadores. Percebeu-se que os itens de proteção não são fornecidos de forma imediata em todos os casos. Ou seja, pode ser que por algum motivo o funcionário precise de um EPI, mas a empresa não o tenha em estoque e por essa razão precise esperar até que a compra do mesmo seja realizada e chegue em suas mãos.

Isso acontece porque, atualmente, o processo para troca de EPIs da empresa funciona da seguinte maneira: o funcionário preenche um formulário de solicitação do produto necessário - que se encontra no Anexo $B$, e entrega ao setor de segurança, que avalia o pedido e verifica se há o equipamento em estoque, caso contrário, é solicitado a cotação do equipamento e efetuado a compra. Este fluxo está melhor detalhado no fluxograma da Figura 3.

Figura 3 - Fluxo de troca de EPIs

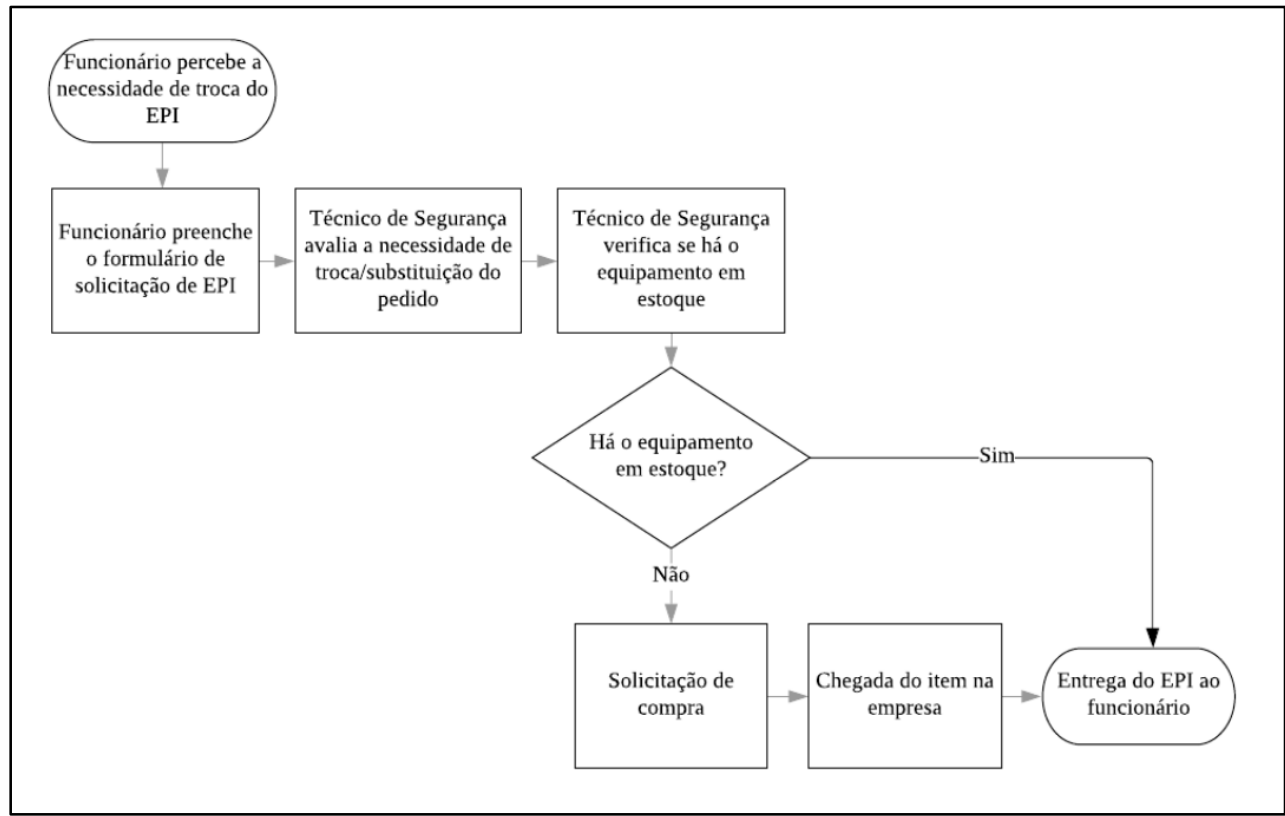

Fonte: Autoria própria (2020).

Quanto às compras, é comum notar que a compra dos itens é feita em diferentes cidades, e diferentes fornecedores, o que impacta no prazo de entrega. Além disso, a empresa em estudo trata-se de uma distribuidora de bebidas de uma companhia multinacional e que possui regras internas de segurança. Um exemplo dessas regras é o catálogo próprio que está em conformidade com a NR 6 e indica quais são os EPIs necessários de acordo com o risco em que o funcionário estará exposto.

O catálogo é disponibilizado e nele é definido as características que cada EPI necessita possuir de acordo com a função do funcionário dentro da empresa, bem como as marcas dos produtos homologados pela companhia. $\mathrm{O}$ mesmo encontra-se descrito, de forma sucinta, no Quadro 4, de acordo com os EPIs que foram analisados neste trabalho. 
Quadro 4-Catálogo de EPIs resumido

\begin{tabular}{|c|c|c|}
\hline EPI & $\begin{array}{l}\text { Quantidade } \\
\text { de marcas } \\
\text { homologadas }\end{array}$ & Funções que utilizam o EPI \\
\hline Botina antiperfurante & 7 & Funcionários do Armazém \\
\hline Botina de borracha / PVC & 6 & Vendedores e Faxineiras \\
\hline Botina antitorção & 7 & Funcionários da Distribuição \\
\hline Botina simples & 5 & $\begin{array}{l}\text { Funcionários com função administrativa e } \\
\text { que acessam o pátio }\end{array}$ \\
\hline Botina com velcro & 7 & Vendedores e promotores \\
\hline Capa de chuva & 6 & Funcionários da Distribuição \\
\hline $\begin{array}{c}\text { Capacete operacional } \\
\text { com jugular }\end{array}$ & 4 & Carreteiros e operadores de empilhadeira \\
\hline Cinta lombar & 3 & $\begin{array}{c}\text { Funcionários da distribuição, armazém e } \\
\text { promotores }\end{array}$ \\
\hline Colete refletivo & 2 & $\begin{array}{c}\text { Funcionários que precisam acessar o pátio } \\
\text { ou armazém }\end{array}$ \\
\hline Conjunto de chuva & 3 & Vendedores e promotores \\
\hline Luva anticorte & 5 & $\begin{array}{l}\text { Funcionários da distribuição, puxada, } \\
\text { armazém e vendas }\end{array}$ \\
\hline Luva de motoqueiro & 1 & Vendedores e promotores \\
\hline Luva nitrílica & 3 & Faxineiras \\
\hline Óculos de sobrepor & 3 & $\begin{array}{c}\text { Funcionários da distribuição, puxada, } \\
\text { armazém e vendas que utilizam óculos de } \\
\text { grau }\end{array}$ \\
\hline Óculos fumê & 3 & Motoristas da distribuição \\
\hline Óculos incolor & 3 & $\begin{array}{l}\text { Funcionários da distribuição, puxada, } \\
\text { armazém e vendas }\end{array}$ \\
\hline
\end{tabular}

Fonte: Autoria própria (2020).

Atualmente, a reposição de itens é realizada conforme a necessidade registrada por algum funcionário ou quando o responsável pelo setor percebe a falta de algum material e solicita a compra. Existe um processo interno para realização das compras, este fluxo está demonstrado no Quadro 5.

Quadro 5 - Processo de aquisição de EPIs

\begin{tabular}{|l|c|}
\hline \multicolumn{1}{|c|}{ Ação } & Responsável \\
\hline 1. Elaborar lista de equipamentos necessários & Setor de Segurança \\
\hline 2. Realizar cotação com pelo menos 3 fornecedores & Setor de Compras \\
\hline 3. Aprovar a cotação mais atraente & Gerente Comercial \\
\hline 4. Separar o pedido e realizar o envio & Fornecedor \\
\hline 5. Deslocamento do pedido até a empresa & Transportadora \\
\hline
\end{tabular}

Fonte: Autoria própria (2020).

Portanto, é visto que o processo de compras é longo e demanda um certo tempo até que o pedido possa chegar na empresa. Este tempo depende de 
inúmeras variáveis, como: tempo de resposta dos fornecedores quanto aos preços, disponibilidade do gerente comercial em aprovar a cotação, além do tempo de deslocamento a depender do local de origem.

Quanto ao registro de estoque, foi constatado que a empresa não possui um sistema para realizá-lo. O registro de saída de materiais somente é realizado por meio da Ficha de EPI - Anexo A, onde é descrito os equipamentos fornecidos a cada funcionário, a data de entrega e o número do Certificado de Aprovação. Portanto, foi visto que o funcionário da Área de Segurança precisa ir até o almoxarifado para saber se há o equipamento necessário, já que não existe um sistema informatizado para controle dos itens em estoque.

Levando estes problemas em consideração e as condições determinadas pela NR6, foi possível perceber que o ideal é que, sempre que o funcionário precise de um EPI, ele esteja prontamente à sua disposição. O dimensionamento adequado do estoque destes materiais e seu controle será eficaz neste sentido, porque visa três objetivos importantes: controle de estoque, economia de gastos e a diminuição dos riscos de incidentes aos funcionários no intervalo entre a solicitação e a chegada do novo equipamento.

\section{ANÁLISE DE DADOS}

Para análise dos dados, primeiramente foi criada uma planilha em Excel para registro a partir dos materiais que se encontram em estoque, assim como suas quantidades para que fossem analisadas as saídas de materiais com base nos funcionários e datas de entrega e devolução. As abas da planilha foram divididas de acordo com o Quadro 6.

Quadro 6 - Abas da planilha

\begin{tabular}{|l|c|}
\hline \multicolumn{1}{|c|}{ Abas } & Caracterização \\
\hline 1. Estoque & Relação de equipamentos e a quantidade em estoque \\
\hline 2. Entrada de Materiais & Registro de todas as entradas de materiais \\
\hline 3. Saída de Materiais & Registro de todas as saídas de materiais \\
\hline 4. Controle de Fichas & Apresenta a ficha de EPI de cada funcionário \\
\hline 5. Solicitações de EPIs & Apresenta as solicitações de EPIs \\
\hline
\end{tabular}

Fonte: Autoria própria (2020).

$\mathrm{Na}$ aba de Estoque foi realizada uma relação com a lista de EPIs utilizados pela empresa, bem como a quantidade de cada um destes itens existentes no estoque. Foi criado um sistema para que futuramente possa ser analisado a situação de estoque em: Estoque Acima, Estoque Normal e Estoque Abaixo, essa análise será feita com base no cálculo de estoque de segurança de cada EPI a fim de saber quando ele deverá ser reposto.

Já na aba de Entrada de Materiais será registrada a data de recebimento de cada Equipamento de Proteção, a descrição do material, a quantidade recebida, o número do Certificado de Aprovação e o valor pago. Esta aba servirá de apoio para a aba de estoque, fazendo com que a quantidade de materiais em estoque aumente, de forma automática, de acordo com a chegada de materiais. Do mesmo modo, a aba de Saída de Materiais auxiliará o controle de estoque de 
modo a atualiza-lo com base no registro de entregas de materiais, com datas e responsável pelo recebimento do equipamento. Esta baixa de estoque será feita por meio da ficha de EPI - Anexo A, onde é descrito todos os dados necessários à aba da planilha.

Posteriormente, a ficha de EPI será utilizada na aba de Controle onde será apontado uma breve cópia da ficha digitada, constando os seguintes dados dos funcionários: nome, função e setor, assim como a lista de EPIs que já foram recebidos por eles com data de entrega e data de devolução. A fim de tornar o trabalho de digitação menos demorado, os dados considerados nesta aba serão apenas das entregas efetuadas no ano de 2017 em diante.

A última aba apresenta a relação de EPIs solicitados pelos funcionários, contendo o EPI necessário e a data de solicitação. Esta aba é preenchida através da entrega dos formulários que está contido no Anexo B.

A alimentação das informações necessárias à planilha será realizada conforme a necessidade. Foi criado um fluxo para entrega de EPIs, onde o responsável pelo setor de segurança recebe o formulário de solicitação, alimenta a planilha e verifica se há o equipamento em estoque, assim como acontece no fluxograma da Figura 3. Já quando ocorre a entrega do material, foi alinhado com os responsáveis pelo setor de segurança a separarem a ficha de EPI e darem a baixa daquela ficha na planilha. Quanto a aba de entrada de materiais, ela será alimentada sempre que ocorrer a chegada de materiais à empresa.

A partir destes dados, e com as informações previamente levantadas, serão realizados os cálculos para levantamento do dimensionamento do estoque. Para isso, serão calculados o tempo de ressuprimento, o estoque de segurança, o ponto de pedido e o lote econômico de compras.

Devido à grande variedade de EPIs utilizados pela empresa e a fim de tornar este trabalho menos extenso, foi priorizado o grupo de Equipamentos com maior saída, de modo que fossem utilizados como amostragem nos cálculos desta pesquisa. É importante ressaltar também que este trabalho não levou em conta os diferentes tamanhos existentes para cada tipo de EPI. Porém, os cálculos poderão ser facilmente replicados com o objetivo de abranger todos os equipamentos e numerações utilizados pela empresa.

Analisando os dados, primeiramente buscou-se calcular o consumo médio de cada EPI explicitado no Quadro 4. Este cálculo foi realizado com base nas fichas lançadas na planilha com datas a partir do ano de 2019 entre os meses de janeiro e setembro. Através dessas entregas, foi calculada a média de consumo mensal de cada um dos equipamentos de proteção entregues no ano. Para encontrar a demanda diária o valor encontrado foi dividido por trinta.

A partir do cálculo anterior, foi possível calcular também o desvio padrão da demanda. O cálculo foi realizado com base na demanda média diária de entrega de cada um dos equipamentos em cada um dos meses analisados, conforme demonstrada no Apêndice A.

O tempo de ressuprimento foi calculado com base na média de tempo com que a empresa frequentemente demanda para conclusão de um pedido. Foi levado em conta os tempos desde o processo de elaboração da lista de compras até o momento em que a empresa recebe e realoca aquele pedido dentro do 
almoxarifado. Da mesma forma, foi calculado o desvio padrão com base nos tempos demandados durante o ano de 2019.

Sendo assim, com os dados necessários em mãos, começou-se a utilizar as fórmulas explicitadas no capítulo 2.2. A primeira fórmula utilizada foi a de Estoque de Segurança a fim de definir o valor do estoque capaz de assegurar a disponibilidade de itens em casos de eventualidades não previstas. Esta fórmula é definida como Equação 2 no referencial teórico deste trabalho. Para tal, adotouse um nível de serviço de $95 \%$, a fim de que o risco de falha seja de apenas $5 \%$. Sendo assim, conforme a Tabela 1, o coeficiente de grau de risco utilizado será de 1,645. Também foram utilizados dados calculados anteriormente, como: demanda média diária, tempo de ressuprimento e desvio padrão de ambos. Os dados utilizados e resultados encontrados estão demonstrados na Tabela 2.

Tabela 2 - Estoque de Segurança

\begin{tabular}{|c|c|c|c|c|c|c|}
\hline EPI & $\begin{array}{l}\text { Nível de } \\
\text { Serviço } \\
(95 \%)\end{array}$ & $\begin{array}{l}\text { Demanda } \\
\text { média } \\
\text { (Diária) }\end{array}$ & $\begin{array}{l}\text { Desvio } \\
\text { padrão } \\
\text { demanda }\end{array}$ & $\begin{array}{l}\text { Tempo } \\
\text { reposição } \\
\text { (Dias) }\end{array}$ & $\begin{array}{l}\text { Desvio } \\
\text { padrão do } \\
\text { tempo } \\
\text { reposição }\end{array}$ & $\begin{array}{l}\text { Estoque } \\
\text { Segurança }\end{array}$ \\
\hline $\begin{array}{c}\text { Botina } \\
\text { antiperfurante }\end{array}$ & 1,645 & 0,09 & 0,06 & 18 & 3,79 & 0,94 \\
\hline $\begin{array}{c}\text { Botina de } \\
\text { borracha / PVC }\end{array}$ & 1,645 & 0,05 & 0,04 & 18 & 3,79 & 0,61 \\
\hline $\begin{array}{c}\text { Botina } \\
\text { antitorção }\end{array}$ & 1,645 & 0,26 & 0,16 & 18 & 3,79 & 2,70 \\
\hline $\begin{array}{c}\text { Botina simples } \\
\text { com biqueira } \\
\text { PVC }\end{array}$ & 1,645 & 0,16 & 0,08 & 18 & 3,79 & 1,50 \\
\hline $\begin{array}{l}\text { Botina com } \\
\text { velcro }\end{array}$ & 1,645 & 0,07 & 0,06 & 18 & 3,79 & 0,80 \\
\hline Capa de chuva & 1,645 & 0,03 & 0,03 & 18 & 3,79 & 0,36 \\
\hline $\begin{array}{l}\text { Capacete } \\
\text { operacional } \\
\text { com jugular }\end{array}$ & 1,645 & 0,03 & 0,03 & 18 & 3,79 & 0,41 \\
\hline Cinta lombar & 1,645 & 0,40 & 0,14 & 18 & 3,79 & 3,49 \\
\hline Colete refletivo & 1,645 & 0,06 & 0,06 & 18 & 3,79 & 0,79 \\
\hline $\begin{array}{l}\text { Conjunto de } \\
\text { chuva }\end{array}$ & 1,645 & 0,03 & 0,03 & 18 & 3,79 & 0,42 \\
\hline Luva anticorte & 1,645 & 1,28 & 0,20 & 18 & 3,79 & 9,38 \\
\hline Luva mista & 1,645 & 0,12 & 0,08 & 18 & 3,79 & 1,28 \\
\hline $\begin{array}{l}\text { Luva } \\
\text { motoqueiro }\end{array}$ & 1,645 & 0,10 & 0,06 & 18 & 3,79 & 1,04 \\
\hline Luva nitrílica & 1,645 & 0,09 & 0,05 & 18 & 3,79 & 0,93 \\
\hline $\begin{array}{l}\text { Óculos de } \\
\text { sobrepor }\end{array}$ & 1,645 & 0,05 & 0,06 & 18 & 3,79 & 0,69 \\
\hline Óculos fumê & 1,645 & 0,07 & 0,03 & 18 & 3,79 & 0,65 \\
\hline Óculos incolor & 1,645 & 0,81 & 0,18 & 18 & 3,79 & 6,26 \\
\hline
\end{tabular}

Fonte: Autoria própria (2020).

O próximo passo do trabalho foi utilizar a Equação 1 para calcular o ponto de pedido de cada um dos itens analisados. Para isto utilizou-se o Estoque de 
Segurança calculado anteriormente, bem como a demanda média diária e o tempo de ressuprimento, conforme demonstrado na Tabela 3.

Tabela 3 - Ponto de Pedido

\begin{tabular}{|c|c|c|c|c|}
\hline EPI & $\begin{array}{c}\text { Demanda } \\
\text { média } \\
\text { (Diária) }\end{array}$ & $\begin{array}{l}\text { Tempo de } \\
\text { reposiç̧ão } \\
\text { (Dias) }\end{array}$ & $\begin{array}{l}\text { Estoque de } \\
\text { Segurança }\end{array}$ & $\begin{array}{l}\text { Ponto de } \\
\text { Pedido }\end{array}$ \\
\hline Botina antiperfurante & 0,09 & 18 & 0,94 & 2,47 \\
\hline Botina de borracha / PVC & 0,05 & 18 & 0,61 & 1,55 \\
\hline Botina antitorção & 0,26 & 18 & 2,70 & 7,30 \\
\hline Botina simples com biqueira PVC & 0,16 & 18 & 1,50 & 4,30 \\
\hline Botina com velcro & 0,07 & 18 & 0,80 & 2,00 \\
\hline Capa de chuva & 0,03 & 18 & 0,36 & 0,82 \\
\hline $\begin{array}{c}\text { Capacete operacional com } \\
\text { jugular }\end{array}$ & 0,03 & 18 & 0,41 & 1,01 \\
\hline Cinta lombar & 0,40 & 18 & 3,49 & 10,69 \\
\hline Colete refletivo & 0,06 & 18 & 0,79 & 1,92 \\
\hline Conjunto de chuva & 0,03 & 18 & 0,42 & 1,02 \\
\hline Luva anticorte & 1,28 & 18 & 9,38 & 32,38 \\
\hline Luva mista & 0,12 & 18 & 1,28 & 3,41 \\
\hline Luva motoqueiro & 0,10 & 18 & 1,04 & 2,91 \\
\hline Luva nitrílica & 0,09 & 18 & 0,93 & 2,53 \\
\hline Óculos de sobrepor & 0,05 & 18 & 0,69 & 1,55 \\
\hline Óculos fumê & 0,07 & 18 & 0,65 & 1,85 \\
\hline Óculos incolor & 0,81 & 18 & 6,26 & 20,80 \\
\hline
\end{tabular}

Fonte: Autoria própria (2020).

Este ponto de pedido é responsável por emitir uma nota de compra ao setor responsável. Mas, para que a compra seja realizada, é preciso saber também a quantidade de material a ser reposta. Para isso, calculou-se o Lote Econômico de Compras, definido pela Equação 3. Esta fórmula necessita das seguintes variáveis: demanda anual, custo de emissão e colocação do pedido, custo de manutenção anual do estoque e valor unitário de cada produto. Dessa forma, as variáveis precisaram ser levantadas juntamente com o responsável pela empresa e estão descritas abaixo.

- Custo de emissão e colocação do pedido: chegou-se ao valor de $R \$ 58,42$, tendo em vista o valor do tempo de quatro funcionários responsáveis por este processo, conforme cálculo do Apêndice B, onde foram considerados salário, encargos trabalhistas e benefícios oferecidos pela empresa aos funcionários. As tarefas necessárias a este processo, bem como seus tempos e responsáveis, estão demonstradas no Quadro 7. É importante ressaltar que o valor do frete não foi considerado neste cálculo devido os fornecedores arcarem com este custo. 
Quadro 7 - Custo de emissão do pedido

\begin{tabular}{|l|c|c|c|}
\hline \multicolumn{1}{|c|}{ Tarefa } & $\begin{array}{c}\text { Tempo } \\
\text { demandado }\end{array}$ & Responsáveis & $\begin{array}{c}\text { Valor } \\
\text { total }\end{array}$ \\
\hline Elaboração do Pedido & 40 minutos & Analista de Segurança & $\mathrm{R} \$ 10,66$ \\
\hline $\begin{array}{l}\text { Cotação com } \\
\text { fornecedores }\end{array}$ & 50 minutos & Estagiária de Compras & $\mathrm{R} \$ 5,96$ \\
\hline Aprovação do Pedido & 12 minutos & $\begin{array}{c}\text { Analista de Segurança, Técnica de } \\
\text { Segurança e Diretor Geral }\end{array}$ & $\mathrm{R} \$ 30,09$ \\
\hline $\begin{array}{l}\text { Organização do } \\
\text { Pedido no estoque }\end{array}$ & 18 minutos & $\begin{array}{c}\text { Analista de Segurança e Técnica de } \\
\text { Segurança }\end{array}$ & $\mathrm{R} \$ 11,03$ \\
\hline $\begin{array}{l}\text { Atualização do } \\
\text { estoque na planilha }\end{array}$ & 3 minutos & Analista de Segurança & $\mathrm{R} \$ 0,80$ \\
\hline
\end{tabular}

Fonte: Autoria própria (2020).

- Demanda anual de cada item: foi feito uma estimativa através da demanda diária calculada no início deste trabalho; ou seja, o valor da demanda de cada item foi multiplicado pela quantidade de dias em um ano (365).

- Custo por unidade: este dado foi calculado com base na média de valores em que cada equipamento é comumente comprado. Porém, este valor foi acrescido de um custo financeiro em razão da taxa de rendimento Selic, tendo em vista que o dinheiro poderia render esta taxa caso não estivesse investido na aquisição do estoque. Neste trabalho, a taxa Selic considerada foi de $5 \%$ ao ano, conforme dados atualizados em outubro de 2019.

- Custo anual de armazenagem de estoque: foram considerados alguns custos referentes à manutenção do estoque de EPIs. A área do estoque é de $6 \mathrm{~m}^{2}$, apesar do imóvel ser próprio e não possuir custos de aluguel, foi considerado o valor médio mensal de aluguel de lotes no bairro que é de $\mathrm{R} \$ 16,68$ o metro quadrado, sendo assim o valor anual seria de $R \$ 1.200,00$. Além disso, foi levado em conta o valor de organização do estoque com base no tempo da Analista de Segurança e da Técnica de Segurança de 25 minutos mensais, resultando em um custo anual de $R \$ 515,13$. A soma destes dois custos é de $R \$ 1.715,13$; porém, foi visto que a sala possui 2,90 metros de altura e é totalmente ocupada por 795 caixas de tamanho $0,30 \times 0,27 \times 0,27$ metros, resultando em um custo de armazenamento de $\mathrm{R} \$ 2,16$ por caixa. Portanto, este valor foi distribuído a cada equipamento levando em conta a quantidade de cada item que cabe nesta caixa, assim como mostra a Tabela 4.

Tabela 4 - Custo de armazenamento

\begin{tabular}{ccc}
\hline EPI & $\begin{array}{c}\text { Demanda média } \\
\text { (Diária) }\end{array}$ & $\begin{array}{c}\text { Tempo de reposição } \\
\text { (Dias) }\end{array}$ \\
Botina antiperfurante & 2 & $\mathrm{R} \$ 1,08$ \\
Botina de borracha / PVC & 2 & $\mathrm{R} \$ 1,08$ \\
Botina antitorção & 2 & $\mathrm{R} \$ 1,08$ \\
Botina simples com biqueira PVC & 2 & $\mathrm{R} \$ 1,08$ \\
Botina com velcro & 2 & $\mathrm{R} \$ 1,08$ \\
Capa de chuva & 10 & $\mathrm{R} \$ 0,22$ \\
Capacete operacional com jugular & 2 & $\mathrm{R} \$ 1,08$ \\
Cinta lombar & 14 & $\mathrm{R} \$ 0,15$ \\
\hline
\end{tabular}




\begin{tabular}{ccc} 
EPI & $\begin{array}{c}\text { Demanda média } \\
\text { (Diária) }\end{array}$ & $\begin{array}{c}\text { Tempo de reposição } \\
\text { (Dias) }\end{array}$ \\
\hline Colete refletivo & 8 & $\mathrm{R} \$ 0,27$ \\
Conjunto de chuva & 3 & $\mathrm{R} \$ 0,72$ \\
Luva anticorte & 25 & $\mathrm{R} \$ 0,09$ \\
Luva mista & 20 & $\mathrm{R} \$ 0,11$ \\
Luva motoqueiro & 20 & $\mathrm{R} \$ 0,11$ \\
Luva nitrílica & 32 & $\mathrm{R} \$ 0,07$ \\
Óculos de sobrepor & 18 & $\mathrm{R} \$ 0,12$ \\
Óculos fumê & 19 & $\mathrm{R} \$ 0,11$ \\
Óculos incolor & 19 & $\mathrm{R} \$ 0,11$ \\
\hline
\end{tabular}

Fonte: Autoria própria (2020).

Portanto, com todos os dados coletados, calculou-se o LEC de cada equipamento de proteção, conforme demonstrado na Tabela 5.

Tabela 5 - Lote Econômico de Compras

\begin{tabular}{|c|c|c|c|c|c|c|}
\hline EPI & $\begin{array}{l}\text { Demanda } \\
\text { média } \\
\text { anual }\end{array}$ & $\begin{array}{l}\text { Custo de } \\
\text { pedido }\end{array}$ & $\begin{array}{l}\text { Custo de } \\
\text { armazen } \\
\text { amento }\end{array}$ & $\begin{array}{l}\text { Valor } \\
\text { unitário }\end{array}$ & $\begin{array}{l}\text { Custo } \\
\text { financeiro }\end{array}$ & LEC \\
\hline $\begin{array}{l}\text { Botina } \\
\text { antiperfurante }\end{array}$ & 31,09 & 58,42 & 1,08 & 72,00 & 3,60 & 3,28 \\
\hline $\begin{array}{c}\text { Botina de borracha / } \\
\text { PVC }\end{array}$ & 18,93 & 58,42 & 1,08 & 22,00 & 1,10 & 6,79 \\
\hline Botina antitorção & 93,28 & 58,42 & 1,08 & 92,90 & 4,65 & 4,53 \\
\hline $\begin{array}{c}\text { Botina simples com } \\
\text { biqueira PVC }\end{array}$ & 56,78 & 58,42 & 1,08 & 43,00 & 2,15 & 6,91 \\
\hline Botina com velcro & 24,33 & 58,42 & 1,08 & 72,00 & 3,60 & 2,91 \\
\hline Capa de chuva & 9,46 & 58,42 & 0,22 & 9,50 & 0,48 & 12,98 \\
\hline $\begin{array}{c}\text { Capacete } \\
\text { operacional com } \\
\text { jugular }\end{array}$ & 12,17 & 58,42 & 1,08 & 29,90 & 1,50 & 4,30 \\
\hline Cinta lombar & 146,00 & 58,42 & 0,15 & 54,00 & 2,70 & 10,52 \\
\hline Colete refletivo & 22,98 & 58,42 & 0,27 & 19,90 & 1,00 & 10,33 \\
\hline Conjunto de chuva & 12,17 & 58,42 & 0,72 & 62,00 & 3,10 & 2,45 \\
\hline Luva anticorte & 466,39 & 58,42 & 0,09 & 16,90 & 0,85 & 58,84 \\
\hline Luva mista & 43,26 & 58,42 & 0,11 & 8,90 & 0,45 & 32,05 \\
\hline Luva motoqueiro & 37,85 & 58,42 & 0,11 & 72,90 & 3,65 & 4,02 \\
\hline Luva nitrílica & 32,44 & 58,42 & 0,07 & 5,50 & 0,28 & 44,86 \\
\hline Óculos de sobrepor & 17,57 & 58,42 & 0,12 & 6,90 & 0,35 & 25,30 \\
\hline Óculos fumê & 24,33 & 58,42 & 0,11 & 4,90 & 0,25 & 40,23 \\
\hline Óculos incolor & 294,70 & 58,42 & 0,11 & 4,90 & 0,25 & $\begin{array}{c}139,9 \\
9\end{array}$ \\
\hline
\end{tabular}

Fonte: Autoria própria (2020). 
Sendo assim, tem-se o Lote Econômico de Compras, responsável por determinar a quantidade de itens a serem compradas através do menor custo possível.

O último cálculo a ser realizado a fim de concluir a proposta de melhoria do estoque foi a de tempo ótimo entre pedidos, Equação 5 do referencial teórico. Sua fórmula é simples e consiste na divisão do LEC pela demanda anual de cada item. Os resultados deste cálculo foram multiplicados por 12 , que é a quantidade de meses em um ano, a fim de que o tempo entre pedidos fosse expresso de forma mensal. Os resultados estão demonstrados na Tabela 6.

Tabela 6 - Tempo ótimo entre pedidos

\begin{tabular}{|c|c|c|c|}
\hline EPI & $\begin{array}{l}\text { Lote econômico } \\
\text { de compras }\end{array}$ & $\begin{array}{l}\text { Demanda } \\
\text { média anual }\end{array}$ & $\begin{array}{l}\text { Tempo ótimo } \\
\text { entre pedidos }\end{array}$ \\
\hline Botina antiperfurante & 3,28 & 31,09 & 1,27 \\
\hline Botina de borracha / PVC & 6,79 & 18,93 & 4,31 \\
\hline Botina antitorção & 4,53 & 93,28 & 0,58 \\
\hline Botina simples com biqueira PVC & 6,91 & 56,78 & 1,46 \\
\hline Botina com velcro & 2,91 & 24,33 & 1,43 \\
\hline Capa de chuva & 12,98 & 9,46 & 16,46 \\
\hline Capacete operacional com jugular & 4,30 & 12,17 & 4,24 \\
\hline Cinta lombar & 10,52 & 146,00 & 0,86 \\
\hline Colete refletivo & 10,33 & 22,98 & 5,39 \\
\hline Conjunto de chuva & 2,45 & 12,17 & 2,42 \\
\hline Luva anticorte & 58,84 & 466,39 & 1,51 \\
\hline Luva mista & 32,05 & 43,26 & 8,89 \\
\hline Luva motoqueiro & 4,02 & 37,85 & 1,27 \\
\hline Luva nitrílica & 44,86 & 32,44 & 16,59 \\
\hline Óculos de sobrepor & 25,30 & 17,57 & 17,28 \\
\hline Óculos fumê & 40,23 & 24,33 & 19,84 \\
\hline Óculos incolor & 139,99 & 294,70 & 5,70 \\
\hline
\end{tabular}

Fonte: Autoria própria (2020).

Portanto, tem-se o tempo ótimo de pedidos, que é uma estimativa de tempo que decorrerá entre os pedidos expressos pelo lote econômico.

\section{PROPOSTA DE MELHORIA}

Anteriormente, foi visto que a empresa não possuía qualquer método de controle e gestão para os Equipamentos de Proteção Individual fornecidos. Para isto, foi implantando uma planilha em Excel para analisar os dados de fichas de EPIs, além das entradas e saídas do estoque. A fim de tornar o processo de gestão mais eficaz e econômico, também foram realizados cálculos através de fórmulas reconhecidas que proporcionaram a definição de conceitos importantes para o dimensionamento de estoques, como: estoque de segurança, ponto de pedido e lote econômico de compras. 
Através dos resultados obtidos foi possível propor um sistema de dimensionamento para os EPIs da empresa em estudo, visando um objetivo simples: o fornecimento de equipamentos através da economia de recursos.

Analisando os resultados obtidos através das fórmulas, foi visto que o Lote Econômico de Compras resultou em um valor muito alto. Porém, a empresa não possui recursos, nem espaço suficientes para a realização de uma compra desta proporção. Sendo assim, a proposta levará em conta a compra de lotes de forma mensal.

Com o objetivo de saber a quantidade de itens de cada tipo que a empresa deve comprar mensalmente, dividiu-se o valor do LEC, que foi calculado anualmente, pelo valor do tempo ótimo entre pedidos. O resultado foi arredondado para cima, obtendo-se os resultados da Tabela 7.

Tabela 7 - Lote mensal de compras

\begin{tabular}{cccc} 
EPI & $\begin{array}{c}\text { Lote econômico } \\
\text { de compras }\end{array}$ & $\begin{array}{c}\text { Tempo ótimo } \\
\text { entre pedidos }\end{array}$ & $\begin{array}{c}\text { Lote mensal } \\
\text { de compras }\end{array}$ \\
$\begin{array}{c}\text { Botina antiperfurante } \\
\text { Botina de borracha / PVC }\end{array}$ & 6,28 & 1,27 & 3 \\
Botina antitorção & 4,53 & 4,31 & 2 \\
Botina simples com biqueira PVC & 6,91 & 0,58 & 8 \\
Botina com velcro & 2,91 & 1,46 & 5 \\
Capa de chuva & 12,98 & 1,43 & 2 \\
Capacete operacional com jugular & 4,30 & 16,46 & 1 \\
Cinta lombar & 10,52 & 4,24 & 2 \\
Colete refletivo & 10,33 & 0,86 & 13 \\
Conjunto de chuva & 2,45 & 5,39 & 2 \\
Luva anticorte & 58,84 & 2,42 & 2 \\
Luva mista & 32,05 & 1,51 & 39 \\
Luva motoqueiro & 4,02 & 8,89 & 4 \\
Luva nitrílica & 44,86 & 1,27 & 4 \\
Óculos de sobrepor & 25,30 & 16,59 & 3 \\
Óculos fumê & 40,23 & 17,28 & 2 \\
Óculos incolor & 139,99 & 5,70 & 3 \\
\hline
\end{tabular}

Fonte: Autoria própria (2020).

A proposta realizada é para que a empresa realize as compras de acordo com o valor determinado para o lote mensal. Sendo assim, sempre que o estoque de algum item for igual ou menor ao ponto de pedido, será emitido uma solicitação de compra ao setor responsável com a quantidade determinada por este lote.

A fim de analisar o método de compras proposto, foi escolhido um dos equipamentos para que fosse realizado uma tabulação dos dados de entregas a partir do sistema adotado. O item escolhido foi a Luva anticorte, tendo em vista que é um equipamento com alta demanda devido à baixa durabilidade. Os dados foram tabulados via planilha - Apêndice C; e plotados em gráfico, assim como demonstra a Figura 4. 
Figura 4 - Análise do estoque da Luva anticorte

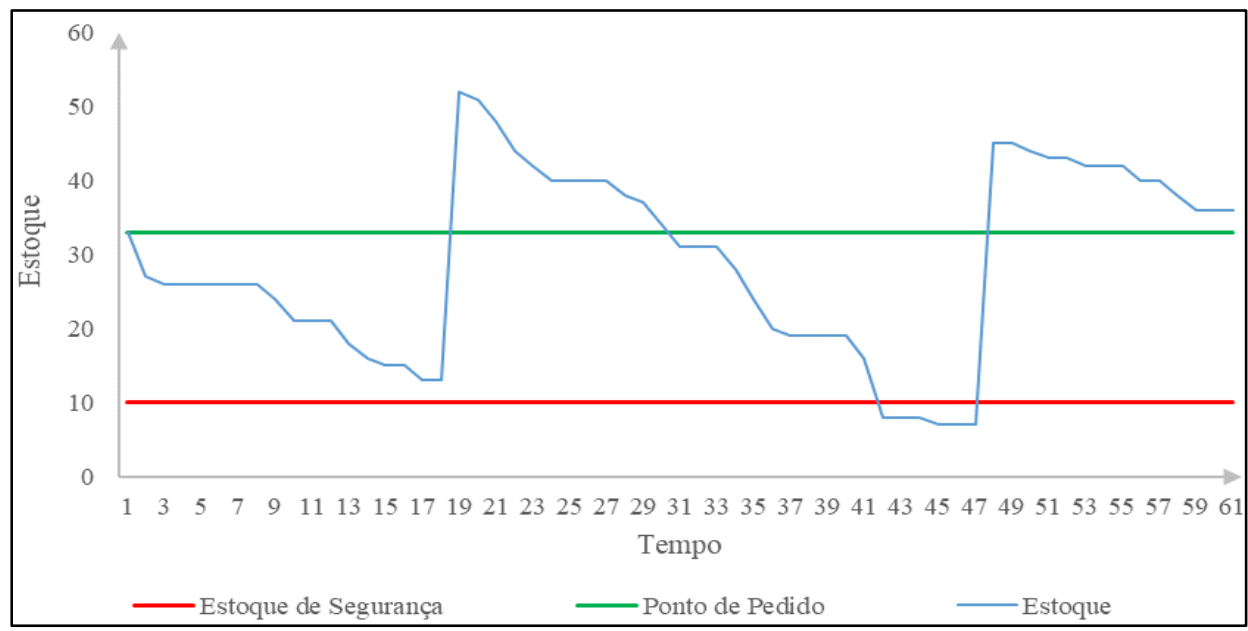

Fonte: Autoria própria (2020).

A ideia do gráfico é fazer uma comparação com o gráfico, modelo dente de Serra, da Figura 1, utilizado no referencial teórico, onde é demonstrado a evolução do estoque conforme a demanda e o recebimento de itens.

Interpretando o gráfico, é possível perceber que o estoque inicial do primeiro dia é igual ao ponto de pedido; portanto, é emitido uma solicitação de compras da quantidade determinada pelo lote mensal, que neste caso é 39 . Até que o pedido chegue na empresa, o estoque vai sendo consumido. 0 mesmo chega na empresa no dia 18, aumentando o nível de estoque. Com o passar do tempo, no dia 30, o estoque chega a um nível inferir ao ponto de ressuprimento, fazendo com que um novo pedido seja realizado. Após o pedido, o estoque vai sendo consumido com maior rapidez, chegando a um nível de estoque de apenas 7 equipamentos, valor inferior ao estoque de segurança calculado. Porém, o pedido chegou no dia 47, não ocorrendo a ruptura de estoque. Dessa forma, o estoque de segurança foi capaz de satisfazer as necessidades de suprimento de Luva anticorte até que o novo pedido chegasse na empresa.

Sendo assim, foi visto que os valores calculados para estoque de segurança, ponto de pedido e lote de compras foi eficaz ao possibilitar o fornecimento de Luva anticorte de forma interrupta aos funcionários.

\section{CONSIDERAÇÕES FINAIS}

O presente estudo teve como objetivo desenvolver um modelo de dimensionamento de estoque para os Equipamentos de Proteção Individual de uma empresa distribuidora de bebidas, através do uso de métricas reconhecidas de gestão de estoques. De acordo com os objetivos traçados no início deste trabalho, é possível concluir que os resultados conseguiram ser alcançados.

Através da análise da antiga gestão praticada pela empresa foi possível identificar inúmeras falhas, mas a principal dela foi a falta de registros. Para isso, foi implantado uma planilha para análise do estoque e das fichas de EPIs, o que tornou o processo de controle mais fácil, tendo em vista que antes não era 
realizado qualquer registro de entrada e saída do estoque. Agora, porém, os responsáveis pelo setor de segurança conseguem saber, através da planilha, o nível do estoque sem precisar se deslocar até o almoxarifado.

A fim de que o estoque fosse capaz de assegurar a disponibilidade de itens através da economia de recursos foram utilizadas métricas de dimensionamento capazes de determinar fatores importantes à gestão de estoques, como: estoque de segurança, ponto de pedido e lote econômico de compras.

Para o desenvolvimento dos cálculos, foi selecionado um grupo dos equipamentos que apresentam maior rotatividade no estoque e que serviram como amostragem para realização deste estudo, porém os cálculos podem ser facilmente replicados com o objetivo de abranger todo o catálogo de EPIs fornecidos pela empresa.

Sendo assim, os resultados obtidos através do ponto de pedido possibilitaram indicar o momento em que cada item deve ser reposto. Já o resultado do LEC proporcionou o entendimento da quantidade que deve ser comprada a cada vez que este ponto de pedido é atingido.

A limitação deste estudo se deu pela falta de análise da marca de cada equipamento. Apesar da empresa possuir marcas específicas para compras, a durabilidade de cada uma delas pode ser diferente, fazendo com que os funcionários realizem a requisição de materiais com maior frequência. Fica como sugestão para estudos futuros justamente isso: a análise de durabilidade em função do preço de cada marca homologada pela empresa, a fim de determinar o custo $\mathrm{x}$ benefício e optar por aquelas que se demonstrarem mais vantajosas.

Portanto, o sistema implantado para dimensionamento e gestão para estoque possibilitou confiabilidade, disponibilidade e economia, apesar de ainda restarem oportunidades de melhorias para controle em função da qualidade e preço. 


\title{
Inventory management and sizing of personal protective equipment from a beverage distribution company
}

\begin{abstract}
This work is the result of a study developed at a Beverage Distributor, where there was no formal method for managing the Personal Protective Equipment stock. In this scenario, purchases were made intuitively and no stock entry and exit records were made. With that, it was necessary to create a spreadsheet to control the PPE Sheets and that would be able to generate data regarding the stock level and the purchasing needs, through the use of simple sizing metrics. Therefore, this work aimed to propose a management model and inventory sizing for safety equipment. For this purpose, the following tools were used: first, the Safety Stock was calculated in order to indicate the minimum stock capable of ensuring the availability of items, then the Order Point was calculated to find the right time to make purchases and, and finally, the number of items that must be purchased using the Economic Purchasing Lot formula. Among the calculations performed, it was possible to notice that the Economic Lot presented a very high and unviable value to the company, due to the high cost and unavailability of space for storage, and for this reason, the formula of Great Time between Orders was used to determine the purchase of economic lots on a monthly basis. The proposed method was analyzed using a graphic, a sawtooth model, which made it possible to visualize the effectiveness of item availability amid stock fluctuation.
\end{abstract}

KEYWORDS: Stock. Personal Protective Equipment. Sizing. 
ALVES, Chaillini Azevedo. Análise do processo de controle de estoque: um estudo de caso na Empresa Sublime Nordeste (Recife). Orientador: Msc. Michele Bezerra Saito. 2017. Trabalho de conclusão de curso (Bacharel em Administração) - Faculdade Damas da Instrução Cristã, Recife, 2017. Disponível em: https://faculdadedamas.edu.br/revistafd/index.php/academico/article/view/ 522/459. Acesso em: 30 maio 2019.

ALVES, Teresa Cristina. Manual de equipamento de proteção individual (Recurso eletrônico). São Carlos: Embrapa Pecuária Sudeste, 2013.

Anuário Estatístico de Acidentes do Trabalho: AEAT 2017. Ministério da Fazenda ... [et al.]. - Vol. 1 (2009) - . - Brasília: MF, 2017.

BALLOU, R. H. Gerenciamento da cadeia de suprimento / logística empresarial. 5. ed. Porto Alegre: Bookman, 2006.

BRASIL. [Constituição (1988)]. Constituição da República Federativa do Brasil de 1988. Brasília, DF: Senado Federal: Centro Gráfico, 1988.

BRASIL. Decreto-Lei n. 5.452, de 10 de maio de 1943. Aprova a Consolidação das Leis do Trabalho. Diário Oficial dos Estados Unidos do Brasil: seção 1, Rio de Janeiro, DF, ano 82, n. 184, p. 11937-11984, 9 ago. 1943.

BRASIL. Ministério do Trabalho e Emprego. NR 6 - EQUIPAMENTO DE PROTEÇÃO INDIVIDUAL - EPI. Portaria MTb n.ㅇ 877, de 24 de outubro de 2018.

CHIAVENATO, I. Administração de materiais: uma abordagem introdutória. 3. ed. Rio de Janeiro: Elsevier, 2005.

CORRÊA, Henrique L.; CORRÊA, Carlos A. Administração de produção e de operações: manufatura e serviços: uma abordagem estratégica. São Paulo: Atlas, 2005.

CRESWELL, J. W. Research design: qualitative, quantitative and mixed methods approaches. California: Sage, 2003.

DIAS, M. A. P. Administração de materiais: uma abordagem logística. 6. ed. São Paulo: Atlas, 2015.

DIEHL, Astor Antônio. Pesquisa em ciências sociais aplicadas: métodos e técnicas. São Paulo: Prentice Hall, 2004.

FENILI, R.R. Gestão de Materiais. Brasília: ENAP - Didáticos, 2015.

GERHARDT, T. E.; SILVEIRA, D. T. Métodos de Pesquisa. 1. ed. Porto Alegre: Editora da UFRGS, 2009.

GIL, A. C. Como elaborar projetos de pesquisa. 4. ed. São Paulo: Atlas, 2002. 
GONÇALVES, E. A. Manual de segurança e saúde no trabalho. São Paulo: LTr, 2000.

GONÇALVES, P. S. Administração de materiais. Rio de Janeiro: Elsevier, 2004.

LAKATOS, E. M.; MARCONI, M. A. Fundamentos metodologia científica. 4. ed. São Paulo: Atlas, 2001.

LINHARES, B. R. et al.. Segurança do trabalho: Uso de EPIS e acidentes na construção civil na cidade de Sobral. In: CONTECC, Foz do Iguaçu, 2016. Artigo. Foz do Iguaçu: [s.n.], 2016.

MARTINS, Petrônio G; ALT, Paulo Renato Campos. Administração de materiais e recursos patrimoniais. 3. ed. São Paulo: Saraiva, 2009.

MOTTA, S. C. S.; MARINS, C. S.. Análise da aplicação da Ferramenta MASP no controle do estoque de uma Usina Siderúrgica. In: Simpósio de Excelência em Gestão e Tecnologia, Rio de Janeiro, 2012. Artigo. Rio de Janeiro: [s. n.], 2012.

PAOLESCHI, Bruno. Almoxarifado e gestão de estoques: [do recebimento, guarda e expedição à distribuição do estoque]. 2. ed. São Paulo: Érica, 2013.

PEINADO, J., GRAEML, A. R. Administração de produção: operações industriais e de serviços. Curitiba: UnicenP, 2007.

POZO, H. Administração de recursos materiais e patrimoniais. 6. ed. São Paulo: Atlas, 2010.

RODRIGUES, Karla Bertolasce Frauches; SANTOS, Nadson Gutemberg Gomes dos. As consequências legais pelo não uso do equipamento de proteção individual no ambiente de trabalho: uma breve análise a luz do ordenamento jurídico brasileiro. In: Âmbito Jurídico, Rio Grande, XX, 2017. Disponível em: http://www.ambito-juridico.com.br/site/?n_link=revista_ artigos_leitura\&artigo_id=19948\&revista_caderno=25. Acesso em 25 mar. 2019.

SALIBA, Tuffi Messias. Curso básico de segurança e higiene ocupacional. 7. ed. São Paulo: LTr, 2016.

SLACK, Nigel; BRANDON-JONES, Alistair; JOHNSTON, Robert. Princípios de administração da produção. São Paulo: Atlas, 2013.

TAYLOR, A. David. Logística na cadeia de suprimentos uma perspectiva gerencial. São Paulo: Pearson, 2006.

TEIXEIRA, Carolina. Administração de recursos materiais para concursos: teoria e exercícios do CESPE comentados. São Paulo: MÉTODO, 2016.

TUBINO, Dalvio Ferrari. Planejamento e controle da produção: teoria e prática. 2. ed. São Paulo: Atlas, 2009.

VALENTIM, Marta L. P.. Métodos qualitativos de pesquisa em Ciência da Informação. São Paulo: Polis, 2005. 
VERGARA, Sylvia C. Projetos e relatórios de pesquisa em administração. 3. ed. Rio de Janeiro: Atlas, 2000.

VIANA, João José. Administração de materiais: Um enfoque prático. 2. ed. São Paulo: Atlas, 2002.

VIEIRA, H. FILHO. Gestão de estoques e operações industriais. Curitiba: IESDE BRASIL SA, 2009.

YIN, Robert K. Estudo de caso: planejamento e métodos. 3. ed. Porto Alegre: Bookman, 2005.

Recebido: 15 Abr. 2020

Aprovado: 14 Out. 2020

DOI: 10.3895/gi.v16n4.11795

Como citar:

LIMA, L.M.; LONGHINI, T.M. Gestão e Dimensionamento de Estoques de Equipamentos de Proteção Individual de Empresa Distribuidora de Bebidas. R. Gest. Industr., Ponta Grossa, v. 16, n. 4, p. 237-271, Out./Dez. 2020.

Disponível em: https://periodicos.utfpr.edu.br/revistagi

Correspondência:

Tatielle Menolli Longhini

Avenida Minas Gerais, Número 5189, Bairro Grã Duquesa, Governador Valadares, Minas Gerais, Brasil

Direito autoral: Este artigo está licenciado sob os termos da Licença Creative Commons-Atribuição 4.0

Internacional.

(c) (i) 


\section{RECIBO DE FORNECIMENTO DE EQUIPAMENTO DE PROTEÇÃO INDIVIDUAL E.P.I.}

\section{"TERMO DE RESPONSABILIDADE"}

Reconheço ter sido orientado previamente sobre os riscos à saúde e dos eventuais agentes agressivos existentes em meu posto de trabalho, tem sido também orientado adequadamente sobre as proteções coletivas e individuais que devo usar. Reconheço estar recebendo todos os Equipamentos de Poteção Indivual - E.P.Is. necessários à minha função e ter sido treinado e orientado quanto à sua utilização correta e obrigatória. Ciente de que não a utilização dos E.P.Is. é falta grave, responsabilizo-me pelo seu uso, conservação e guarda, ficando a empresa autorizada a efetuar descontos em meu salário, em caso de danos injustificados dos mesmos, sem prejuízo da dispensa por justa causa no caso de recusa sem justificativa para seu uso. Os E.P.Is. serão entregues conforme a seguir nas respectivas datas em que assinarei comprovando o recebimento do mesmo.

"OBRIGAČ̃óES QUANTO AO EPI"

Empregador: Adquirir o tipo adequado à atividade do empregado. Fornecer ao empregado somente o E.P.I. aprovado pela MTA e de empresas cadastradas no DNSST/MTA. Treinar o trabalhador sobre seu uso adequado. Tornar obrigatório seu uso. Substituí-lo, imediatamente quando danificado ou extraviado. Responsabilizar-se pela sua higienização e manutenção periódica. Comunicar ao MTA qualquer irregularidade observada no E.P.I.

Empregado: usá-lo apenas para a finalidade a que se destina. Responsabilizar-se por sua guarda e conservação. Comunicar ao empregador qualquer alteração que o torne improprio para uso.

\begin{tabular}{|c|c|c|c|c|c|c|}
\hline \multicolumn{5}{|l|}{ NOME: } & \multirow{2}{*}{\multicolumn{2}{|c|}{ 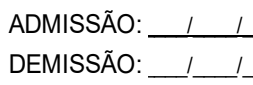 }} \\
\hline \multicolumn{5}{|l|}{ FUNÇÃO: } & & \\
\hline \multicolumn{5}{|c|}{ ASSINATURA: } & & \\
\hline Quantidade & Descrição do EPI / Modelo / Marca & C.A. & \begin{tabular}{|l|} 
Data de entrega \\
\end{tabular} & Data de devolução & Assinatura & Visto \\
\hline & & & & & & \\
\hline & & & & & & \\
\hline & & & & & & \\
\hline & & & & & & \\
\hline & & & & & & \\
\hline & & & & & & \\
\hline & & & & & & \\
\hline & & & & & & \\
\hline & & & & & & \\
\hline & & & & & & \\
\hline & & & & & & \\
\hline & & & & & & \\
\hline & & & & & & \\
\hline & & & & & & \\
\hline & & & & & & \\
\hline & & & & & & \\
\hline & & & & & & \\
\hline
\end{tabular}




\begin{tabular}{|c|c|c|c|c|c|c|}
\hline \multicolumn{7}{|c|}{$\begin{array}{l}\text { Solicito por meio deste, } \mathrm{EPI} / \text { Uniforme. } \\
\text { Estou ciente que o receberei apenas mediante a entrega do equipamento anterior e após validação do setor de segurança } \\
\text { quanto a real necessidade de troca. }\end{array}$} \\
\hline Data da solicitação: & 1 & & \begin{tabular}{|l|} 
Nome do funcionário: \\
Função: \\
Setor: \\
\end{tabular} & & & \\
\hline Descrição & Tam. & Quant. & Descrição & Tam. & Quant. & \\
\hline Camisa & & & Luva Anti-Corte & & & \\
\hline Calça & & & Luva motoqueiro & & & Assinatura: \\
\hline Botina Armazem & & & Óculos & & & \\
\hline Botina de velcro & & & Jaqueta & & & \\
\hline Botina anti-torção & & & Cinta lombar & & & \\
\hline Sapato de segurança & & & Capacete & & & Gestor imediato \\
\hline Bota Borracha & & & Conjunto Chuva & & & \\
\hline Boné & & & Capa de chuva amarela & & & \\
\hline
\end{tabular}


APÊNDICE A - CÁLCULO DO DESVIO PADRÃO DA DEMANDA

\begin{tabular}{|c|c|c|c|c|c|c|c|c|c|c|}
\hline EPIs & Jan & Fev & Mar & Abr & Mai & Jun & Jul & Ago & Set & $\sigma_{D}$ \\
\hline $\begin{array}{c}\text { Botina } \\
\text { antiperfurante }\end{array}$ & 0,07 & 0,17 & 0,17 & 0,03 & 0,03 & 0,07 & 0,03 & 0,03 & 0,03 & 0,06 \\
\hline $\begin{array}{c}\text { Botina de } \\
\text { borracha / PVC }\end{array}$ & 0,00 & 0,07 & 0,07 & 0,10 & 0,00 & 0,07 & 0,00 & 0,00 & 0,00 & 0,04 \\
\hline $\begin{array}{c}\text { Botina } \\
\text { antitorção }\end{array}$ & 0,10 & 0,43 & 0,00 & 0,13 & 0,30 & 0,43 & 0,17 & 0,17 & 0,30 & 0,16 \\
\hline $\begin{array}{c}\text { Botina simples } \\
\text { com biqueira } \\
\text { PVC }\end{array}$ & 0,10 & 0,17 & 0,20 & 0,10 & 0,17 & 0,03 & 0,27 & 0,27 & 0,07 & 0,08 \\
\hline $\begin{array}{c}\text { Botina com } \\
\text { velcro }\end{array}$ & 0,00 & 0,00 & 0,07 & 0,07 & 0,13 & 0,13 & 0,00 & 0,00 & 0,07 & 0,06 \\
\hline Capa de chuva & 0,00 & 0,07 & 0,07 & 0,03 & 0,00 & 0,03 & 0,03 & 0,03 & 0,00 & 0,03 \\
\hline $\begin{array}{c}\text { Capacete } \\
\text { operacional } \\
\text { com jugular }\end{array}$ & 0,00 & 0,03 & 0,00 & 0,07 & 0,03 & 0,07 & 0,07 & 0,00 & 0,00 & 0,03 \\
\hline Cinta lombar & 0,47 & 0,60 & 0,27 & 0,27 & 0,30 & 0,47 & 0,47 & 0,50 & 0,20 & 0,14 \\
\hline Colete refletivo & 0,00 & 0,10 & 0,17 & 0,03 & 0,10 & 0,07 & 0,07 & 0,00 & 0,07 & 0,06 \\
\hline $\begin{array}{c}\text { Conjunto de } \\
\text { chuva }\end{array}$ & 0,07 & 0,00 & 0,07 & 0,03 & 0,00 & 0,00 & 0,00 & 0,00 & 0,00 & 0,03 \\
\hline Luva anticorte & 1,10 & 1,23 & 1,23 & 1,30 & 1,40 & 1,03 & 1,03 & 0,80 & 1,40 & 0,20 \\
\hline Luva mista & 0,07 & 0,00 & 0,20 & 0,13 & 0,20 & 0,07 & 0,07 & 0,03 & 0,17 & 0,08 \\
\hline $\begin{array}{l}\text { Luva } \\
\text { motoqueiro }\end{array}$ & 0,03 & 0,10 & 0,13 & 0,13 & 0,07 & 0,03 & 0,03 & 0,20 & 0,10 & 0,06 \\
\hline Luva nitrílica & 0,07 & 0,03 & 0,10 & 0,00 & 0,03 & 0,10 & 0,10 & 0,03 & 0,17 & 0,05 \\
\hline $\begin{array}{l}\text { Óculos de } \\
\text { sobrepor }\end{array}$ & 0,00 & 0,17 & 0,07 & 0,03 & 0,03 & 0,00 & 0,00 & 0,03 & 0,00 & 0,06 \\
\hline Óculos fumê & 0,00 & 0,03 & 0,10 & 0,10 & 0,07 & 0,07 & 0,07 & 0,07 & 0,07 & 0,03 \\
\hline Óculos incolor & 0,73 & 0,90 & 0,63 & 0,63 & 0,90 & 0,60 & 0,47 & 0,47 & 0,63 & 0,18 \\
\hline
\end{tabular}


APÊNDICE B - CÁLCULO DO VALOR DO MINUTO DE CADA FUNCIONÁRIO

\begin{tabular}{|c|c|c|c|c|}
\hline Dados & Estagiária & $\begin{array}{c}\text { Analista de } \\
\text { Segurança }\end{array}$ & $\begin{array}{c}\text { Técnica de } \\
\text { Segurança }\end{array}$ & $\begin{array}{c}\text { Diretor } \\
\text { Geral }\end{array}$ \\
\hline Salário base & $\mathrm{R} \$ 700,00$ & $\mathrm{R} \$ 1668,60$ & $\mathrm{R} \$ 2224,00$ & $\mathrm{R} \$ 13000,00$ \\
\hline Vale transporte & $\mathrm{R} \$ 160,00$ & $\mathrm{Não}$ possui & $\mathrm{Não}$ possui & $\mathrm{Não}$ possui \\
\hline Vale refeição & $\mathrm{R} \$ 264,00$ & $\mathrm{R} \$ 264,00$ & $\mathrm{R} \$ 264,00$ & $\mathrm{R} \$ 264,00$ \\
\hline Fração 13o salário & $\mathrm{Não}$ possui & $\mathrm{R} \$ 138,49$ & $\mathrm{R} \$ 184,59$ & $\mathrm{R} \$ 1079,00$ \\
\hline Fração de férias & $\mathrm{R} \$ 77,70$ & $\mathrm{R} \$ 185,21$ & $\mathrm{R} \$ 246,86$ & $\mathrm{R} \$ 1443,00$ \\
\hline FGTS & Não possui & $\mathrm{R} \$ 133,49$ & $\mathrm{R} \$ 177,92$ & $\mathrm{R} \$ 1040,00$ \\
\hline $\begin{array}{c}\text { Fração do FGTS com 13ㅇ } \\
\text { salário e férias }\end{array}$ & Não possui & $\mathrm{R} \$ 23,36$ & $\mathrm{R} \$ 31,14$ & $\mathrm{R} \$ 182,00$ \\
\hline INSS & Não possui & $\mathrm{R} \$ 333,72$ & $\mathrm{R} \$ 444,80$ & $\mathrm{R} \$ 2600,00$ \\
\hline $\begin{array}{c}\text { Fração do INSS com 13ㅇ } \\
\text { salário e férias }\end{array}$ & $\mathrm{Não}$ possui & $\mathrm{R} \$ 66,74$ & $\mathrm{R} \$ 88,96$ & $\mathrm{R} \$ 520,00$ \\
\hline Valor total & $\mathrm{R} \$ 1201,70$ & $\mathrm{R} \$ 2831,62$ & $\mathrm{R} \$ 3662,27$ & $\mathrm{R} \$ 2012800$ \\
\hline Valor do minuto & $\mathrm{R} \$ 0,1138$ & $\mathrm{R} \$ 0,2664$ & $\mathrm{R} \$ 0,3468$ & $\mathrm{R} \$ 1,9061$ \\
\hline
\end{tabular}


APÊNDICE C - EVOLUÇÃO DO ESTOQUE DE LUVA ANTICORTE

\begin{tabular}{|c|c|c|c|c|c|}
\hline Dia & $\begin{array}{c}\text { Estoque } \\
\text { inicial }\end{array}$ & Consumo & Entrada & $\begin{array}{c}\text { Estoque } \\
\text { final }\end{array}$ & Ocorrência \\
\hline 1 de agosto & 33 & 6 & 0 & 27 & $\begin{array}{c}\text { Pedido de } \\
\text { Compra }\end{array}$ \\
\hline 2 de agosto & 27 & 1 & 0 & 26 & \\
\hline 3 de agosto & 26 & 0 & 0 & 26 & \\
\hline 4 de agosto & 26 & 0 & 0 & 26 & \\
\hline 5 de agosto & 26 & 0 & 0 & 26 & \\
\hline 6 de agosto & 26 & 0 & 0 & 26 & \\
\hline 7 de agosto & 26 & 0 & 0 & 26 & \\
\hline 8 de agosto & 26 & 2 & 0 & 24 & \\
\hline 9 de agosto & 24 & 3 & 0 & 21 & \\
\hline 10 de agosto & 21 & 0 & 0 & 21 & \\
\hline 11 de agosto & 21 & 0 & 0 & 21 & \\
\hline 12 de agosto & 21 & 3 & 0 & 18 & \\
\hline 13 de agosto & 18 & 2 & 0 & 16 & \\
\hline 14 de agosto & 16 & 1 & 0 & 15 & \\
\hline 15 de agosto & 15 & 0 & 0 & 15 & \\
\hline 16 de agosto & 15 & 2 & 0 & 13 & \\
\hline 17 de agosto & 13 & 0 & 0 & 13 & \\
\hline 18 de agosto & 13 & 0 & 39 & 52 & $\begin{array}{c}\text { Chegada } \\
\text { de Material }\end{array}$ \\
\hline 19 de agosto & 52 & 1 & 0 & 51 & \\
\hline 20 de agosto & 51 & 3 & 0 & 48 & \\
\hline 21 de agosto & 48 & 4 & 0 & 44 & \\
\hline 22 de agosto & 44 & 2 & 0 & 42 & \\
\hline 23 de agosto & 42 & 2 & 0 & 40 & \\
\hline 24 de agosto & 40 & 0 & 0 & 40 & \\
\hline 25 de agosto & 40 & 0 & 0 & 40 & \\
\hline 26 de agosto & 40 & 0 & 0 & 40 & \\
\hline 27 de agosto & 40 & 2 & 0 & 38 & \\
\hline 28 de agosto & 38 & 1 & 0 & 37 & \\
\hline 29 de agosto & 37 & 3 & 0 & 34 & \\
\hline 30 de agosto & 34 & 3 & 0 & 31 & $\begin{array}{c}\text { Pedido de } \\
\text { Compra }\end{array}$ \\
\hline 31 de agosto & 31 & 0 & 0 & 31 & \\
\hline 1 de setembro & 31 & 0 & 0 & 31 & \\
\hline 2 de setembro & 31 & 3 & 0 & 28 & \\
\hline 3 de setembro & 28 & 4 & 0 & 24 & \\
\hline
\end{tabular}




\begin{tabular}{|l|l|l|l|l|l|}
\hline 4 de setembro & 24 & 4 & 0 & 20 & \\
\hline 5 de setembro & 20 & 1 & 0 & 19 & \\
\hline 6 de setembro & 19 & 0 & 0 & 19 & \\
\hline 7 de setembro & 19 & 0 & 0 & 19 & \\
\hline 8 de setembro & 19 & 0 & 0 & 19 & \\
\hline 9 de setembro & 19 & 3 & 0 & 16 & \\
\hline 10 de setembro & 16 & 8 & 0 & 8 & \\
\hline 11 de setembro & 8 & 0 & 0 & 8 & \\
\hline 12 de setembro & 8 & 0 & 0 & 8 & \\
\hline 13 de setembro & 8 & 1 & 0 & 7 & \\
\hline 14 de setembro & 7 & 0 & 0 & 7 & \\
\hline 15 de setembro & 7 & 0 & 0 & 7 & \\
\hline 16 de setembro & 7 & 1 & 39 & 45 & de Material \\
\hline 17 de setembro & 45 & 0 & 0 & 45 & \\
\hline 18 de setembro & 45 & 1 & 0 & 44 & \\
\hline 19 de setembro & 44 & 1 & 0 & 43 & \\
\hline 20 de setembro & 43 & 0 & 0 & 43 & \\
\hline 21 de setembro & 43 & 1 & 0 & 42 & \\
\hline 22 de setembro & 42 & 0 & 0 & 42 & \\
\hline 23 de setembro & 42 & 0 & 0 & 42 & \\
\hline 24 de setembro & 42 & 2 & 0 & 40 & \\
\hline 25 de setembro & 40 & 0 & 0 & 40 & \\
\hline 26 de setembro & 40 & 2 & 0 & 38 & \\
\hline 27 de setembro & 38 & 2 & 0 & 36 & \\
\hline 28 de setembro & 36 & 0 & 0 & 36 & \\
\hline 29 de setembro & 36 & 0 & 0 & 36 & \\
\hline 30 de setembro & 36 & 2 & 0 & 34 & \\
\hline
\end{tabular}

